\title{
Haemodynamic response to intravenous hydralazine in patients with pulmonary hypertension
}

\author{
MICHAEL D McGOON, JAMES B SEWARD, RONALD E VLIETSTRA, MAURICE H CHOO, \\ THOMAS P MOYER, GUY S REEDER
}

From the Division of Cardiovascular Diseases and Internal Medicine and the Section of Clinical Chemistry, Mayo Clinic and Mayo Foundation, Rochester, Minnesota, USA

SUMmaRY The acute pulmonary and systemic haemodynamic response to low $(0 \cdot 15 \mathrm{mg} / \mathrm{kg})$ and high $(0.30 \mathrm{mg} / \mathrm{kg})$ doses of intravenous hydralazine was evaluated in 26 consecutive patients with severe pulmonary hypertension due to cor pulmonale (nine patients), primary pulmonary hypertension (11 patients), or pulmonary embolism (six patients). Hydralazine did not cause a significant change in pulmonary arterial resistance or pressure in any group but produced a significant reduction in systemic resistance, which correlated with plasma concentration, and a significant increase in pulmonary blood flow index in all groups. Ten patients who experienced a reduction in pulmonary arterial resistance of at least $5 \mathrm{U} \cdot \mathrm{m}^{2}$ after administration of hydralazine had higher initial values for pulmonary arterial resistance and systemic resistance and a lower pulmonary blood flow index than those who did not respond. Maintenance oral hydralazine treatment during nine to 36 months of follow up did not seem to affect symptoms or mortality. These results indicate that hydralazine has limited value in acutely reducing pulmonary arterial pressure or affecting clinical outcome in patients with pulmonary hypertension.

The treatment of symptomatic pulmonary hypertension continues to be a perplexing problem, and results have generally been disappointing for both primary and secondary forms. Studies of pharmacological agents, including isoproterenol, ${ }^{1-4}$ tolazoline, ${ }^{4-7}$ phentolamine, ${ }^{8}$ verapamil, ${ }^{9}$ nifedipine, ${ }^{10}$ diazoxide, ${ }^{11-13}$ isosorbide dinitrate, ${ }^{14}$ and prostaglandins, ${ }^{15}$ have usually concerned only a few patients and the results have been promising but equivocal. Recent reports ${ }^{16-18}$ have suggested that the vasodilator hydralazine substantially reduces pulmonary resistance in some patients with primary pulmonary hypertension or cor pulmonale, perhaps by a prostaglandin mediated mechanism. ${ }^{19}$

A thorough study of pulmonary hypertension and the results of drug intervention is difficult. The disease is much less common than systemic hypertension, is relatively silent until advanced, and necessitates catheterisation to confirm the diagnosis and quantify the haemodynamic state. Evaluation of the haemodynamic effect of drugs also necessitates invasive testing because a change in symptoms, exercise

Dr McGoon is the 1982-3 recipient of an American Colleze of Cardiology/Merck Adult Cardiolosy Fellowhip Training Award.

Accepted for publication 26 July 1983 tolerance, or oxygen saturation may not reliably reflect pulmonary haemodynamics.

The present study was designed to investigate the acute pulmonary and systemic haemodynamic response to intravenous hydralazine in a large group of patients with pulmonary hypertension and to evaluate the relation between the acute response and the subsequent clinical course of patients taking hydralazine orally in a maintenance dose. Intravenous administration of the drug and acute measurements were used to minimise the potential contribution of spontaneous fluctuations in pulmonary haemodynamics that may occur in these patients. ${ }^{20}$

\section{Patients and methods}

The study group comprised 26 consecutive patients with severe pulmonary hypertension who had been referred to the cardiac catheterisation laboratory between 1 April 1980 and 30 November 1981. All patients had presented with symptoms compatible with pulmonary hypertension (that is, exertional dyspnoea or chest pain, or both). Patients with valvular or congenital heart disease were excluded.

Three subgroups of patients, based on the apparent underlying cause of pulmonary hypertension, were 
Table 1 Lung function data from nine patients with parenchymal lung disorders

\begin{tabular}{|c|c|c|c|c|c|c|c|c|c|c|c|}
\hline Case & Diagnosis & $\begin{array}{l}\text { Pattem of } \\
\text { defect }\end{array}$ & $F V C(l)$ & $F E V_{1}(l)$ & $F E F($ lmin) & $T L C(l)$ & $R V(l)$ & $\underset{\left(\operatorname{ml} / \text { min/mim } H_{g}\right)}{\mathrm{D}_{\mathrm{g}}}$ & $\begin{array}{l}\mathrm{PO}_{2}^{\star} \\
\left(\min \mathrm{Hg}^{\star}\right)\end{array}$ & $\begin{array}{l}\mathrm{PCO}_{2}^{\star} \\
\left(\min \mathrm{H}_{g}\right)\end{array}$ & $\begin{array}{l}p H^{*} \\
\text { (units) }\end{array}$ \\
\hline $\begin{array}{l}1 \\
2 \\
3 \\
4 \\
5 \\
6 \\
7 \\
8 \\
9\end{array}$ & $\begin{array}{l}\text { PSS } \\
\text { PSS } \\
\text { PSS } \\
\text { Uncertain } \\
\text { Sarcoid } \\
\text { COPD } \\
\text { PSS } \\
\text { Fibrosis } \\
\text { Sarcoid }\end{array}$ & $\begin{array}{l}\text { Restrictive } \\
\text { Restrictive } \\
\text { Restrictive } \\
\text { Restrictive } \\
\text { Restrictive } \\
\text { Obstructive } \\
\text { Mired } \\
\text { Mixed } \\
\text { Mixed }\end{array}$ & $\begin{array}{l}2.5(89) \mathrm{f} \\
3.4(86) \\
2.1(73) \\
2.9(94) \\
\text { No data } \\
1.5(58) \\
1.7(77) \\
2.7(67) \\
1.2(40)\end{array}$ & $\begin{array}{l}2.1(88) t \\
2.6(89) \\
1.8(84) \\
2.3(91) \\
\text { ilable) } \\
0.6(31) \\
1.3(76) \\
1.6(56) \\
1.0(40)\end{array}$ & $\begin{array}{l}1.2(50) \dagger \\
2.1(46) \\
2.0(111) \\
1.9(55) \\
0.9 \quad(16) \\
0.9(40) \\
0.6(17) \\
1.4(48)\end{array}$ & $\begin{array}{l}3.9(78) \dagger \\
4.8(81) \\
3.0(64) \\
4.5(90) \\
4.0(96) \\
3.2(79) \\
4.4(67) \\
-\end{array}$ & $\begin{array}{ll}1.3 & (59)+ \\
1.4 & (71) \\
0.9 & (47) \\
1.5 & (84) \\
& \\
2.3 & (142) \\
1.5 & (82) \\
1.7 & (64) \\
- & \end{array}$ & $\begin{array}{r}10 \\
9 \\
10 \\
7 \\
8 \\
7 \\
11 \\
-\end{array}$ & $\begin{array}{l}49 \\
49 \\
53 \\
43 \\
61 \\
45 \\
46 \\
62 \\
26\end{array}$ & $\begin{array}{l}34 \\
36 \\
34 \\
31 \\
39 \\
50 \\
39 \\
28 \\
48\end{array}$ & $\begin{array}{l}7 \cdot 35 \\
7 \cdot 41 \\
7 \cdot 52 \\
7 \cdot 45 \\
7 \cdot 45 \\
7 \cdot 34 \\
7 \cdot 44 \\
7 \cdot 45 \\
7 \cdot 34\end{array}$ \\
\hline
\end{tabular}

*Determined while patient was breathing room air.

tNumbers in parentheses = percentage of predicted normal for each value based on age, sex, and height.

COPD, chronic obstructive pulmonary disease; $D_{I} \mathrm{CO}$, diffusing capecity of the lungs for carbon monoxide; FEF, forced expiratory flow rate at midexpiration FEV 1 , forced expiratory volume in one second; FVC, forced vital capacity; $\mathrm{PCO}_{2}$ and $\mathrm{PO}_{2}$, partial pressure of carbon dioxide and oxygen; PSS, progressife systemic sclerosis; RV, residual volume; TLC, total lung capacity.

identified. (1) Chronic restrictive or obstructive pulmonary disease (or both), confirmed by lung function testing (Table 1), was noted in nine patients (seven women and two men), whose mean age was 54 years (range 33 to 81 years). (2) Primary pulmonary hypertension (no detectable underlying cause) was found in 11 (three female and eight male) patients, whose mean age was 44 years (range 16 to 67 years). (3) Pulmonary embolism was detected in six patients (four women and two men), whose mean age was 48 years (range 35 to 69 years). All six patients had a history compatible with pulmonary embolism; in addition, ventilation perfusion lung scanning was performed in two, pulmonary angiography in two, and lung biopsy in one.

All patients underwent catheterisation of the right side of the heart. An arterial cannula was used for blood sampling and continuous monitoring of systemic pressure. The following measurements were obtained with the patients supine and resting: pulmonary and systemic arterial pressure, oxygen saturations, pulmonary wedge pressure (10 patients), left atrial pressure (eight patients), left ventricular pressure (three patients), and $\mathrm{pH}$ and arterial blood gas measurements. At each stage of the study cardiac output was determined twice by using indocyanine green dye dilution techniques with injection into the pulmonary artery and sampling in the peripheral systemic artery. Six sets of measurements were obtained: $(a)$ control values, $(b)$ after 10 minutes of breathing $100 \%$ oxygen, (c) 10 minutes after resumption of breathing room air to confirm return to control values, $(d) 10$ minutes after intravenous administration of $0.15 \mathrm{mg} / \mathrm{kg}$ (low dose) hydralazine, (e) 10 minutes after intravenous administration of $0.30 \mathrm{mg} / \mathrm{kg}$ (high dose) hydralazine, and $(f)$ 20-30 minutes after administration of high dose hydralazine (late plateau). The high dose hydralazine was given about $15 \mathrm{~min}$ utes after the low dose. Standard formulas were used to calculate systemic and pulmonary blood flow indices, indexed systemic and pulmonary arterial resis- tance, and arteriovenous oxygen difference.

Blood hydralazine concentrations were obtained 10 minutes after low dose and high dose injections and during the late plateau period in 15 patients. Total hydralazine (parent and active metabolites) was measured by a modification of the method of Reece et al., ${ }^{21}$ in which liquid chromatography was used and the drug was detected by monitoring the intensity of the fluorescence of the tetrazolo[3,4- $\alpha]$ phthalazine derivative. The hydralazine reference standard was a gift from Ciba-Geigy Corporation, Summit, New Jersey.

"Apparent" plasma hydralazine concentrations were measured after conversion to the tetrazolo[ $[3,4$ $\alpha]$ phthalazine derivative as a means of identifying all active circulating hydralazine metabolites. The predominant form (more than 90\%) of hydralazine in plasma is hydralazine pyruvic acid hydrazone, which is produced after interaction of hydralazine with pyruvic acid. Methods designed to measure this metabolite selectively have yielded highly variable results. ${ }^{21}$ We therefore used a technique that converted all circulating hydralazine and metabolites to a single entity for measurement purposes and reported the result as apparent total hydralazine concentration.

After catheterisation patients were given hydralazine orally at the discretion of the referring physician. Clinical follow up (nine to 36 months; mean 15 months) was obtained by office or telephone interviews with the patient or, if deceased, with a relative.

The significance of any observed difference between haemodynamic values obtained before and after intervention was evaluated by use of Student's paired $t$ test or analysis of variance.

\section{Results}

ACUTE HAEMODYNAMIC EFFECTS OF OXYGEN AND HYDRALAZINE

The haemodynamic data obtained during the control period, during administration of $100 \%$ oxygen, and 
Table 2 Summary of patient characteristics and haemodynamic data. Values are means \pm SEM

\begin{tabular}{|c|c|c|c|c|c|c|c|c|c|c|}
\hline \multirow{2}{*}{$\begin{array}{l}\text { Cause of } \\
\text { pulmonary } \\
\text { hypertension }\end{array}$} & \multirow{2}{*}{$\begin{array}{l}\text { No of } \\
\text { patients }\end{array}$} & \multicolumn{2}{|c|}{ Age (yr) } & \multirow[t]{2}{*}{ Intervention } & \multirow[t]{2}{*}{$Q_{P}\left(l / \min / m^{2}\right)$} & \multirow[t]{2}{*}{$P p(\operatorname{man} H g)$} & \multirow[t]{2}{*}{$R_{p}\left(U \cdot m^{2}\right)$} & \multirow[t]{2}{*}{$P s(m m H g)$} & \multirow[t]{2}{*}{$R s\left(U m^{2}\right)$} & \multirow[t]{2}{*}{$\mathrm{AVO}_{2} \Delta\left(v_{0} / \%\right)$} \\
\hline & & Mean & Range & & & & & & & \\
\hline $\begin{array}{l}\text { Primary } \\
\text { lung } \\
\text { disease } \\
\text { Primary } \\
\text { pulmonary } \\
\text { hypertension }\end{array}$ & 11 & 48 & $16-67$ & $\begin{array}{l}\text { Control } \\
100 \% \mathrm{O}_{2} \\
\text { Low dose } \mathrm{H} \\
\text { High dose } \mathrm{H} \\
\text { Control } \\
100 \% \mathrm{O}_{2} \\
\text { Low dose } \mathrm{H} \\
\text { High dose } \mathrm{H} \\
\text { Control } \\
100 \% \mathrm{O}_{2} \\
\text { Low dose } \mathrm{H} \\
\text { High dose } \mathrm{H}\end{array}$ & $\begin{array}{l}2.2 \pm 0.3 \\
2.2 \pm 0.3 \\
2.5 \pm 0.3 \\
3.2 \pm 0.5^{\star} \\
2.6 \pm 0.3 \\
2.5 \pm 0.4 \\
3.0 \pm 0.4 \dagger \\
3.3 \pm 0.4^{\star} \\
1.9 \pm 0.3 \\
2.0 \pm 0.4 \\
2.4 \pm 0.3 \\
2.6 \pm 0.4 \dagger\end{array}$ & $\begin{array}{l}54 \pm 4 \\
52 \pm 5 \\
56 \pm 4 \\
57 \pm 3 \\
64 \pm 5 \\
62 \pm 6 \\
65 \pm 5 \\
68 \pm 5 \\
47 \pm 3 \\
50 \pm 3 \\
53 \pm 3 \\
53 \pm 5\end{array}$ & $\begin{array}{l}27 \pm 3 \\
27 \pm 4 \\
26 \pm 4 \\
22 \pm 4 \\
30 \pm 6 \\
31 \pm 7 \\
27 \pm 5 \\
26 \pm 5 \\
28 \pm 5 \\
30 \pm 7 \\
25 \pm 4 \\
24 \pm 3\end{array}$ & $\begin{array}{l}89 \pm 5 \\
96 \pm 7 \star \\
89 \pm 5 \\
79 \pm 4 \dagger \\
90 \pm 3 \\
94 \pm 3 \\
85 \pm 4 \\
75 \pm 4 \dagger \\
89 \pm 8 \\
91 \pm 6 \\
90 \pm 5 \\
78 \pm 6\end{array}$ & $\begin{array}{l}44 \pm 5 \\
49 \pm 6 t \\
41 \pm 6 \\
28 \pm 4^{\star} \\
40 \pm 5 \\
44 \pm 7 \\
34 \pm 5 t \\
26 \pm 4^{\star} \\
55 \pm 12 \\
57 \pm 15 \\
42 \pm 8 \\
30 \pm 7 \dagger\end{array}$ & $\begin{array}{l}5.8 \pm 0.5 \\
6.7 \pm 0.6 \\
5.8 \pm 0.5 \\
5.1 \pm 0.5 \\
5.6 \pm 0.7 \\
5.8 \pm 0.6 \\
5.4 \pm 0.6 \\
4.9 \pm 0.5 \\
7.6 \pm 1.1 \\
7.7 \pm 1.2 \\
6.6 \pm 0.7 \\
5.8 \pm 0.6+\end{array}$ \\
\hline
\end{tabular}

Significantly different from control value $\left({ }^{\star} \mathrm{p}<0.01\right.$ and $\left.\mathrm{tp}<0.05\right)$.

$\mathrm{AVO}_{2} \Delta$, arteriovenous oxygen difference; $\mathrm{H}$, hydralazine; Pp, mean pulmonary arterial pressure; Ps, mean systemic arterial pressure; Qp, pulmonary blood flow index; Rp, total pulmonary vascular resistance (indexed); Rs, systemic arterial resistance (indexed).

after intravenous injection of low dose and high dose hydralazine are provided in Table 2 and depicted in Fig. 1. All patients had abnormally raised pulmonary arterial pressures and resistance while breathing room air. Among patients in whom measurements of pulmonary wedge, left atrial, or left ventricular pressure were obtained, all had normal values (less than $15 \mathrm{~mm}$ $\mathrm{Hg}$ ) except one (a pulmonary wedge pressure of $20 \mathrm{~mm} \mathrm{Hg}$ ).

Inhalation of $100 \%$ oxygen did not affect the mean pulmonary arterial pressure in any patient subgroup. Systemic resistance and pressure were slightly increased during inhalation of oxygen in all groups but reached statistical significance only in the group with parenchymal lung disease $(p<0.05$ and 0.01 , respectively).

Hydralazine decreased pulmonary arterial resistance in all groups but the decrease was not significant (Fig. 1). In contrast, systemic arterial resistance was significantly reduced (groups 1 and $2 p<0.01$; group $3 \mathrm{p}<0.05$ ). Cardiac index increased significantly in patients with parenchymal lung disease $(p<0.01)$, primary pulmonary hypertension $(\mathrm{p}<0.01)$, and pulmonary embolism $(p<0.05)$. No significant change in mean pulmonary arterial pressure was noted in any group.

Immediate adverse effects of hydralazine were transient and relatively mild. Five patients experienced asymptomatic hypotension (systolic blood pressure of less than $85 \mathrm{~mm} \mathrm{Hg}$ ) during or shortly after catheterisation, and this complication was managed with administration of fluids. Nausea and vomiting developed in two patients, and one patient had a prolonged (two hour) sinus tachycardia (heart rate of more than 120 beats $/ \mathrm{min}$ ).

RESPONDERS $V$ NON-RESPONDERS

To determine whether differences in baseline characteristics might predict the acute haemodynamic response to hydralazine, patients were classified as responders or non-responders. Patients were characterised as responders if indexed total pulmonary arterial resistance decreased by more than 5 Wood units $\left(\mathrm{U} \cdot \mathrm{m}^{2}\right)$ after administration of either low dose or high dose hydralazine or at the time of late plateau measurements. Non-responders had decreases of less than $5 \mathrm{U} \cdot \mathrm{m}^{2}$ or increases in pulmonary arterial resistance.

Table 3 summarises the characteristics of each group. Differences among subgroups were not significant, though patients with primary pulmonary hypertension seemed least likely to respond. A higher proportion of females $(50 \%)$ than males $(25 \%)$ were responders. The mean age was somewhat higher for the responders than for the non-responders.

Table 4 shows the observed haemodynamic responses after the intravenous administration of hydralazine. Control pulmonary arterial resistance was significantly higher in responders than in nonresponders $(p<0.025)$. The absolute decrease in mean pulmonary arterial resistance was greater for the responders (as expected by definition), and the percentage decrease in resistance among the responders was also significantly greater than for the nonresponders $(-31 \cdot 2 \pm 2 \cdot 8 \% v-8 \cdot 5 \pm 3 \cdot 1 \%)$. Responders also had a higher baseline systemic arterial resistance $(p<0.01)$ and a lower pulmonary blood flow index $(p<0.005)$ than non-responders. Although systemic arterial resistance decreased and pulmonary blood flow index increased significantly after administration of hydralazine in both groups ( $\mathrm{p}<0.001$ in all cases), the magnitude of change was greater in the responders (Table 4).

Among the responding patients pulmonary arterial resistance was maximally reduced after administration of high dose hydralazine in all but one patient. Five non-responders experienced their lowest pulmonary arterial resistance after receiving low dose hydralazine 

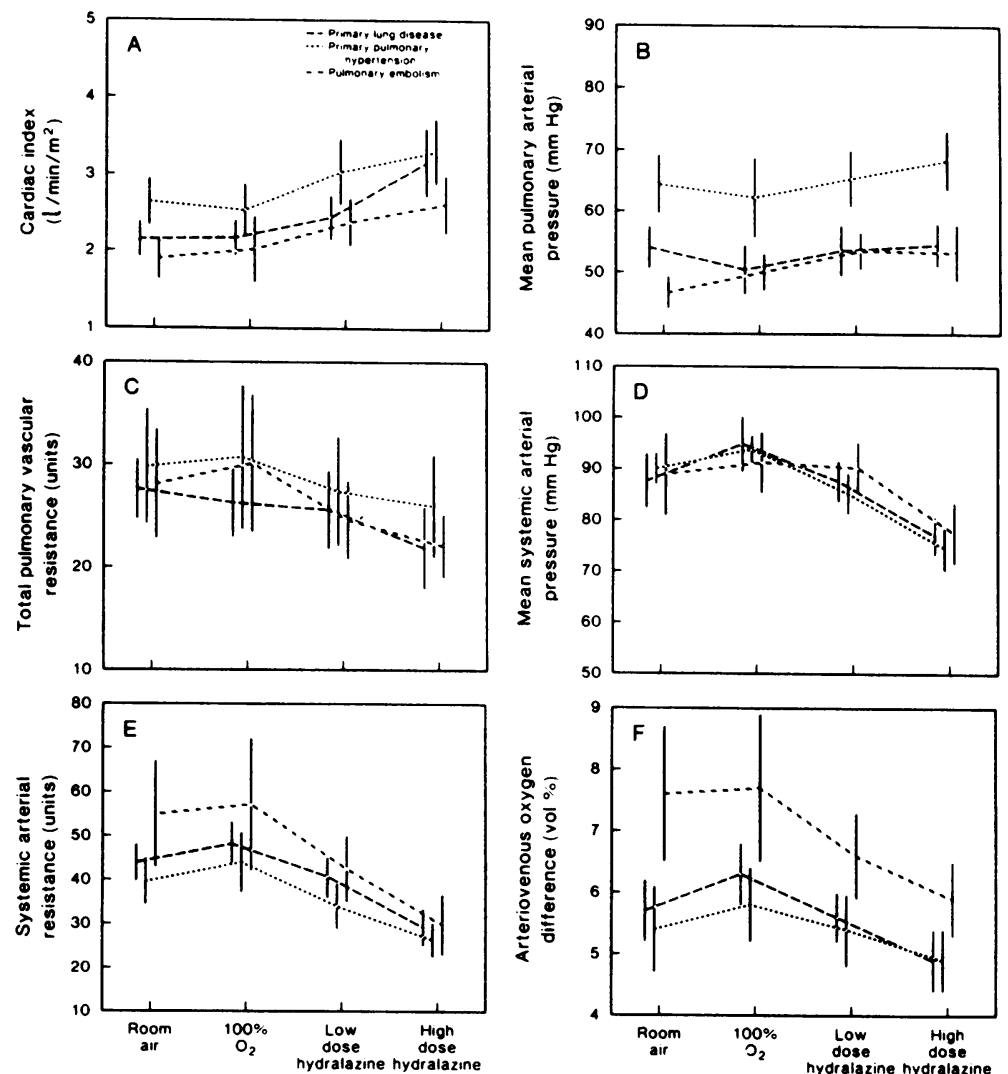

Fig 1 Haemodynamic measurements obtained during each phase of the study (control, after inhalation of $100 \%$ oxygen, and after administration of low dose and high dose hydralazine), depicted from each group. (A) Cardiac index (pulmonary blood flow index for patients with intracardiac shunts). (B) Mean pulmonary arterial pressure. (C) Total pulmonary vascular resistance. (D) Mean systemic arterial pressure. (E) Systemic arterial resistance. (F) Arteriovenous oxygen difference. Values are given as mean \pm standard error of the mean. Levels of significance are given in Table 2.

Table 3 General characteristics of responders and nonresponders

\begin{tabular}{|c|c|c|}
\hline & $\begin{array}{l}\text { Responders } \\
(n=10)\end{array}$ & $\begin{array}{l}\text { Non-responders } \\
(n=16)\end{array}$ \\
\hline \multicolumn{3}{|l|}{ Groups } \\
\hline $\begin{array}{l}\text { Parenchymal lung disease } \\
\text { Primary pulmonary hypertension } \\
\text { Pulmonary embolism }\end{array}$ & $\begin{array}{l}5 \\
2 \\
3\end{array}$ & $\begin{array}{l}4 \\
9 \\
3\end{array}$ \\
\hline \multicolumn{3}{|l|}{ Sex } \\
\hline $\begin{array}{l}\text { Male } \\
\text { Female }\end{array}$ & 3 & 9 \\
\hline \multicolumn{3}{|l|}{ Age (years) } \\
\hline Mean & 55 & 44 \\
\hline $\begin{array}{l}\text { Range } \\
\text { Clinical right heart failure }\end{array}$ & $33-81$ & $16-67$ \\
\hline Clincar higit heart läure & & \\
\hline
\end{tabular}

but had a subsequent increase after receiving the higher dose. Four non-responders had a slight additional decrease in pulmonary arterial resistance (less than $2 \mathrm{U} \cdot \mathrm{m}^{2}$ ) during the late plateau phase, but in no case did a non-responder become a responder.

Plasma hydralazine concentration at the time of lowest pulmonary arterial resistance was $0.94 \pm 0.29 \mu \mathrm{g} / \mathrm{ml}$ for responders (five patients) and $0.64 \pm 0.11 \mu \mathrm{g} / \mathrm{ml}$ for non-responders (10 patients); the difference was not significant. Despite the higher concentration in responders, no significant correlation was noted between the peak decrease in pulmonary arterial resistance and the concomitant hydralazine 
Table 4 Acute haemodynamic effects of hydralazine in responders and non-responders (mean $\pm S E M$ )

\begin{tabular}{|c|c|c|c|c|c|}
\hline & $Q D\left(l\right.$ min $\left./ m^{2}\right)$ & $P p(\operatorname{men} H g)$ & $R p\left(U \cdot m^{2}\right)$ & $P s(\operatorname{mm} H g)$ & $R s\left(U \cdot m^{2}\right)$ \\
\hline $\begin{array}{l}\text { Responders } \\
\text { Control } \\
\text { Hydralazine } \\
\text { Mean \% change } \\
\text { p }\end{array}$ & $\begin{array}{l}1 \cdot 7 \pm 0.1 \\
2 \cdot 6 \pm 0.2 \\
51 \cdot 2 \pm 6 \cdot 1 \\
<0.001\end{array}$ & $\begin{array}{l}58 \pm 3 \\
59 \pm 4 \\
2 \cdot 9 \pm 4 \cdot 3 \\
\text { NS }\end{array}$ & $\begin{array}{l}36 \pm 5 \\
25 \pm 4 \\
-31 \cdot 2 \pm 2 \cdot 8 \\
<0 \cdot 001\end{array}$ & $\begin{array}{l}92 \pm 5 \\
80 \pm 5 \\
-12 \cdot 9 \pm 4 \cdot 7 \\
<0 \cdot 05\end{array}$ & $\begin{array}{l}58 \pm 7 \\
33 \pm 5 \\
-41 \cdot 2 \pm 2 \cdot 7 \\
<0 \cdot 001\end{array}$ \\
\hline $\begin{array}{l}\text { Control } \\
\text { Hydralazine* } \\
\text { Mean \% change } \\
\text { p }\end{array}$ & $\begin{array}{l}2.7 \pm 0.2 \\
3 \cdot 4 \pm 0.4 \\
21.4 \pm 5 \cdot 5 \\
<0.001\end{array}$ & $\begin{array}{l}56 \pm 4 \\
60 \pm 4 \\
9 \cdot 1 \pm 3 \cdot 3 \\
<0 \cdot 02\end{array}$ & $\begin{array}{l}23 \pm 3 \\
22 \pm 3 \\
-8 \cdot 5 \pm 3 \cdot 1 \\
\text { NS }\end{array}$ & $\begin{array}{l}88 \pm 3 \\
78 \pm 3 \\
-9.8 \pm 3 \cdot 2 \\
<0.02\end{array}$ & $\begin{array}{l}36 \pm 3 \\
27 \pm 3 \\
-23 \cdot 8 \pm 3 \cdot 7 \\
<0 \cdot 001\end{array}$ \\
\hline
\end{tabular}

*Dose that produced the lowest pulmonary arterial resistance.

NS, not significant. For other abbreviations see Table 2.

concentration. This finding was in contrast to a significant $(p<0.05)$ correlation between hydralazine concentration and reduction in systemic arterial resistance (Fig. 2).

\section{FOLLOW UP}

Follow up data were obtained for 24 patients and are summarised in Table 5. Two patients (one responder and one non-responder) were lost to follow up. Nine patients were responders and 15 were nonresponders; the -mean duration of follow up was 16 months and 15 months after catheterisation, respectively. Of the two living responders, one had taken hydralazine orally ( $200 \mathrm{mg}$ daily) since his admission to hospital, and he noted alleviation of his dyspnoea. The living responder who had not taken hydralazine also felt better. Of the eight living non-responders, four were taking hydralazine orally (60 to $200 \mathrm{mg}$ daily) and two of these four had subjective improvement. Two of four living non-responders who were not taking hydralazine felt better. The use and dose of hydralazine had no significant effect on mortality in responders, non-responders, or the group as a whole.

\section{Discussion}

This study of the haemodynamic responses of a large group of patients with pulmonary hypertension shows that the intravenous administration of hydralazine produces no acute improvement in pulmonary resistance or pressure in most patients. The predominant haemodynamic effects of the drug were increased pulmonary blood flow related to enhanced cardiac index, which was secondary to decreased systemic arterial resistance and left ventricular afterload. Pulmonary haemodynamic improvement, when it occurred, tended to be in those patients with the most abnormal baseline haemodynamic state. The clinical response of patients with pulmonary hypertension was poor, regardless of whether hydralazine was given
Table 5 Follow up data from responders and non-responders *

\begin{tabular}{lcc}
\hline & $\begin{array}{c}\text { Responders } \\
(n=9)\end{array}$ & $\begin{array}{l}\text { Non-responders } \\
(n=15)\end{array}$ \\
\hline $\begin{array}{l}\text { Duration of follow up (months) } \\
\text { Mean }\end{array}$ & 16 & 15 \\
$\begin{array}{l}\text { Range } \\
\text { Patients taking maintenance } \\
\text { oral hydralazine } \\
\quad \text { Mean daily dose (mg) }\end{array}$ & $12-35$ & $9-36$ \\
$\quad$ Alive & 6 & 7 \\
$\quad \begin{array}{c}\text { Decreased symptoms } \\
\text { Patients not taking } \\
\text { maintenance oral } \\
\text { hydralazinet }\end{array}$ & 1 & 125 \\
$\quad$ Alive & 4 & 2 \\
Decreased symptoms & 3 & \\
\hline
\end{tabular}

*Two patients (one responder and one non-responder) were lost to follow up.

tTwo responders and one non-responder died in the hospital and thus had no opportunity to receive maintenance oral hydralazine.

orally on a chronic basis after the haemodynamic study.

These conclusions differ from those of previous studies. Rubin and Peter ${ }^{16} 17$ reported that four patients with primary pulmonary hypertension and 12

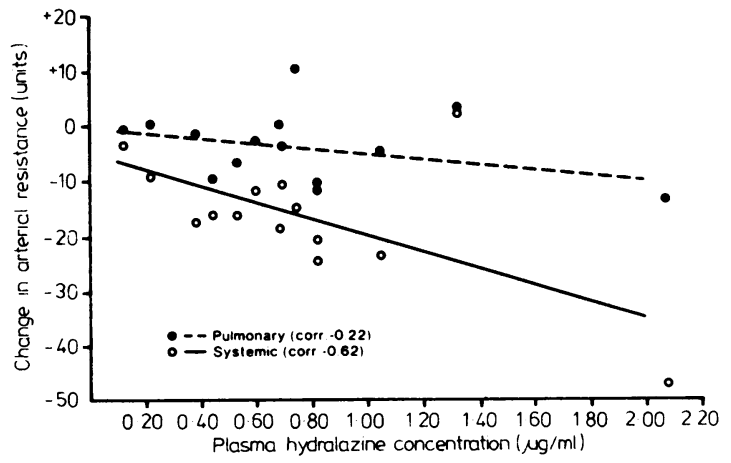

Fig 2 Relation of plasma hydralazine concentration to change in arterial resistance. No correlation was found between drug concentration and change in pulmonary arterial resistance, but a strong correlation $(p<0.05)$ was found between drug concentration and change in systemic arterial resistance. 
patients with cor pulmonale showed a significant reduction in pulmonary arteriolar resistance. LupiHerrera $e t a l .{ }^{18}$ found a beneficial effect in a subgroup of patients with primary pulmonary hypertension who had only modestly abnormal resting pulmonary haemodynamics. Other authors, however, have reported relatively small decreases in pulmonary vascular resistance compared with the systemic vascular response and have also noted a higher incidence of adverse effects after administration of hydralazine. ${ }^{22}$

A recent study ${ }^{23}$ indicated that hydralazine may reduce right ventricular end diastolic pressure, even in the absence of a decrease in pulmonary arterial pressure, and that the reduction may be correlated with a change in total pulmonary vascular resistance. In our patients, right ventricular end diastolic pressure decreased by at least $10 \%$ in only six patients and, on the average, increased slightly in both responders and non-responders (from $16 \pm 2 \mathrm{~mm} \mathrm{Hg}$ to $18 \pm 2 \mathrm{~mm} \mathrm{Hg}$ and from $13 \pm 1 \mathrm{~mm} \mathrm{Hg}$ to $14 \pm 2 \mathrm{~mm} \mathrm{Hg}$, respectively).

The reasons for the different results in the present study may be related to differences in patient population and study methods. Although underlying causes were similar, resting pulmonary arterial pressures and resistance were somewhat higher in these patients than those observed in previous reports. In addition, haemodynamic data in previous studies were usually obtained before and after oral administration of hydralazine for $\mathbf{4 8}$ hours. The temporal separation of control and test measurements may account for some differences in observed responses, either because of a potentially more gradual onset of response or because of possible spontaneous variability of haemodynamic state over time.

The results of this study suggest that hydralazine has limited value in the treatment of severe pulmonary hypertension in terms of either acute response or clinical outcome. Although the pulmonary arterial resistance or pressure (or both) may improve slightly in some patients, most patients show little benefit and others may experience increased pulmonary arterial pressures or systemic hypotension. Treatment of pulmonary hypertension with hydralazine should be done cautiously, if at all, and under close observation. There is no evidence to date that chronic use of hydralazine affects the prognosis of patients with this disease. Perhaps some clinical benefit may occur because of the non-pulmonary haemodynamic effects of hydralazine-for example, decreased systemic vascular resistance, increased cardiac output, enhanced tissue oxygenation, or a combination of these factors; however, these hypotheses remain unproved.

We thank Lila $R$ Elveback, Section of Medical Research Statistics, for help with statistical analysis.

\section{References}

1 Lee TD Jr, Roveti GC, Ross RS. The hemodynamic effects of isoproterenol on pulmonary hypertension in man. Am Heart $\mathcal{F}$ 1963; 65: 361-7.

2 Mentzer RM Jr, Alegre CA, Nolan SP. The effects of dopamine and isoproterenol on the pulmonary circulation. F Thorac Cardiovasc Surg 1976; 71: 807-14.

3 Shettigar UR, Hultgren HN, Specter M, Martin R, Davies DH. Primary pulmonary hypertension: favorable effects of isoproterenol. $N$ Engl f Med 1976; 295: 1414 5.

4 Daoud FS, Reeves JT, Kelly DB. Isoproterenol as a potential pulmonary vasodilator in primary pulmonary hypertension. Am f Cardiol 1978; 42: 817-22.

5 Rudolph AM, Paul MH, Sommer LS, Nadas AS. Effects of tolazoline hydrochloride (Priscoline) on circulatory dynamics of patients with pulmonary hypertension. Am Heart $\mathcal{f}$ 1958; 55: 424-32.

6 Rao BNS, Moller JH, Edwards JE. Primary pulmonary hypertension in a child: response to pharmacologic agents. Circulation 1969; 40: 583-7.

7 Dresdale DT, Schultz M, Michtom RJ. Primary pulmonary hypertension. I. Clinical and hemodynamic study. Am $\mathcal{F}$ Med 1951; 11: 686-705.

8 Ruskin JN, Hutter AM Jr. Primary pulmonary hypertension treated with oral phentolamine. Ann Intern Med 1979; 90: 772-4.

9 Landmark K, Refsum AM, Simonsen S, Storstein O. Verapamil and pulmonary hypertension. Acta Med Scand 1978; 204: 299-302.

10 Camerini F, Alberti E, Klugmann S, Salvi A. Primary pulmonary hypertension: effects of nifedipine. $\mathrm{Br}$ Heart f 1980; 44: 352-6.

11 Wang SWS, Pohl JEF, Rowlands DJ, Wade EG. Diazoxide in treatment of primary pulmonary hypertension. $\mathrm{Br}$ Heart $\mathcal{F}$ 1978; 40: 572-4.

12 Honey M, Cotter L, Davies N, Denison D. Clinical and haemodynamic effects of diazoxide in primary pulmonary hypertension. Thorax 1980; 35: 269-76.

13 Klinke WP, Gilbert JAL. Diazoxide in primary pulmonary hypertension. $N$ Engl f Med 1980; 302: 91-2.

14 Danahy DT, Tobis JM, Aronow WS, Chetty K, Glauser F. Effects of isosorbide dinitrate on pulmonary hypertension in chronic obstructive pulmonary disease. Clin Pharmacol Ther 1979; 25: 541-8.

15 Szczeklik J, Dubiel JS, Mysik M, Pyzik Z, Krol R, Horzela $T$. Effects of prostaglandin $E_{1}$ on pulmonary circulation in patients with pulmonary hypertension. $\mathrm{Br}$ Heart f 1978; 40: 1397-1401.

16 Rubin LJ, Peter RH. Oral hydralazine therapy for primary pulmonary hypertension. $N$ Engl f Med 1980; 302: 69-73.

17 Rubin LJ, Peter RH. Hemodynamics at rest and during exercise after oral hydralazine in patients with cor pulmonale. Am f Cardiol 1981; 47: 116-22.

18 Lupi-Herrera E, Sandoval J, Seoane M, Bialostozky D. The role of hydralazine therapy for pulmonary arterial hypertension of unknown cause. Circulation 1982; 65: $645-50$.

19 Rubin LJ, Lazar JD. Influence of prostaglandin synthesis inhibitors on pulmonary vasodilatory effects of 
hydralazine in dogs with hypoxic pulmonary vasoconstriction. $\mathcal{F}$ Clin Invest 1981 ; 67: 193-200.

20 Rich S, Martinez J, Lam W, Rosen KM. Captopril as treatment for patients with pulmonary hypertension: problem of variability in assessing chronic drug treatment. Br Heart $\mathcal{F}$ 1982; 48: 272-7.

21 Reece PA, Cozamanis I, Zacest R. Selective highperformance liquid chromatographic assays for hydralazine and its metabolites in plasma of man. $f$ Chromatogr 1980; 181: 427-40.

22 Packer M, Greenberg B, Massie B, Dash H. Deleterious effects of hydralazine in patients with pulmonary hypertension. N Engl f Med 1982; 306: 1326-31.

23 Rubin LJ, Handel F, Peter RH. The effects of oral hydralazine on right ventricular end-diastolic pressure in patients with right ventricular failure. Circulation 1982; 65: 1369-73.

Requests for reprints to Dr M D McGoon, c/o Section of Publications, Mayo Clinic, Rochester, Minnesota 55905, USA. 